\title{
Antes muerta que sencilla. Chile como sociedad DE CASTAS EN LA CHICA DEL CRILlÓN DE JoAQuín EDWARD BELLO*
}

\author{
Miguel Alvarado Borgoño**
}

\section{Resumen}

En este artículo analizamos la novela La Chica del Crillón del novelista y periodista chileno Joaquín Edwards Bello, publicada en Santiago en 1935. Se trata de un retrato de su época sobre el cual, específicamente, argumentamos que se trata de una obra que es la expresión preclara de la visión de mundo de los grupos dominantes chilenos, como voz autocrítica de los grupos hegemónicos en el Chile de la primera mitad del siglo XX, de los cuales el autor tanto empírico como textual de este libro son fieles representantes.

Palabras clave: Joaquín Edwards Bello, mujer y oligarquía, capital social, Chile en la primera mitad del siglo XX.

\section{Before dead that humble. Chile as a Caste SOciety in La CHica del CRILlón by JoAquín EdWARd Bello}

\begin{abstract}
In this article, we analyze the novel La Chica del Crillón by Chilean novelist and journalist Joaquín Edwards Bello, published in Santiago in 1935. It is a portrait of his time about which, specifically, we argue that it is a work that is the expression A prelude to the worldview of Chilean dominant groups, as the self-critical voice of the hegemonic groups in Chile in the first half of the twentieth century, of which both the empirical and textual author of this book are faithful representatives.
\end{abstract}

Keywords: Joaquín Edwards Bello, woman and oligarchy, social capital, Chile in the first half of the 20th century. 


\section{Introducción. Más que una ideología de clase, un modo de mirar y mirarse}

«[...] tenemos que arreglarlo, pensarlo mejor para nosotros, por ejemplo, dar trabajo a las personas que hoy día ya están jubiladas. Ahí ya tienes una solución [...]» Santiago de Chile, 2016.

Catalina Edwards1

Al leer la novela La Chica del Crillón de Joaquín Edwards Bello (18871968), publicada por primera vez en 1935, y desarrollar una interpretación filológica crítica y situada, surge hoy decir que Chile es una sociedad «altamente estamentalizada». A pesar de que ello resulta, sin duda, un lugar común, se trata de una constante articulación de la intelectualidad chilena, con un «aire de familia» a la apelación y la conminación realizada por José Victorino Lastarria, ${ }^{2}$ como punta del iceberg de un movimiento social mesocrático y masivo que se comenzó a expresar en la naciente clase media en el siglo XIX, cuando dijo: «soy inteligente y lo luzco» ${ }^{3}$. Los ejemplos de esa estamentalización son tan evidentes como el describir este fraccionamiento social en el paso del siglo XIX al siglo XX, segmentación producto de una articulación de poder social y económico, que en el siglo antepasado se encontraba en manos de una cincuentena

La periodista de la señal de TV Mega, Catalina Edwards, «está viviendo un duro momento luego de emitir un comentario en el programa Mucho Gusto con respecto al tema de las AFP [Administradora de Fondos de Pensiones]. La conductora de noticias ha recibido diversos tipos de amenazas [...] por las redes sociales donde además se filtraron sus datos personales y un llamado a apedrear su domicilio [...] La filtración sumó los datos de su marido, el empresario Pablo Tisne alto ejecutivo de una compañía que tiene acciones en AFP» (La mañana párr. 1-4).

2 José Victorino Lastarria (Rancagua, 22 de marzo de 1817 - Santiago, 14 de junio de 1888). Pensador liberal, escritor, catedrático, intelectual y político. Diputado en siete periodos, entre 1843 y 1870, y Senador en dos periodos consecutivos, entre 1876 y 1885 . Ministro durante los gobiernos de José Joaquín Pérez y Aníbal Pinto. Embajador de Chile en Perú. Ministro de la Corte de Apelaciones y de la Corte Suprema. Decano de la Facultad de Filosofía de la Universidad de Chile (Ctd. por Subercaseaux 3).

3 Tuve que luchar con el ridículo y la difamación, y fui desde el principio burlón para evitar el ridículo y violento para suprimir la difamación. De aquí la susceptibilidad, el excesivo amor propio, el mal genio que me atribuyen y que en general no han sido en mí naturales, sino obra del cálculo y premeditación, tal vez obra del hábito, pero no de un hábito vicioso e inveterado, porque me he vencido siempre que ha sido necesario, y jamás me ha costado vencerme. En la prensa, en los debates parlamentarios, he tenido que ser soberbio, contra lo que me parecía que indicaba desprecio o ridículo, altanero contra el poder que pretendía avasallarme, dogmático y perentorio contra todo error, implacable contra los especuladores y traficantes de la moral y de la política [...]» (Radio Viaducto). 
de familias y que, paradójicamente, hoy en el siglo XXI se haya en manos de una decena o algo más de grupos familiares oligárquicos. Aseverar que el capitalismo genera más capitalismo es también un lugar común, Marx lo dijo ${ }^{4}$ y asimismo afirmó proféticamente que la burguesía en sus distintas expresiones y variantes es la clase social más eficiente de la historia. Nuestra aproximación a esta novela del pasado siglo se sostiene esencialmente en nuestra opinión de que ella es la expresión de la oligarquía terrateniente que se entronca con la alta burguesía chilena de la primera mitad del siglo XX. Es la oligarquía la clase social de Edwards Bello con sus círculos y segmentos, grupos sociales que son cuestionados por él, ridiculizados, pero ante todo representados: el autor textual es un sujeto de esa oligarquía terrateniente emergente que está siendo reemplazada por la burguesía y que sobrevive y equilibra, aún hoy, entre la posesión del capital económico y del capital social (Bourdieu, 2002). La novela La Chica del Crillón es una obra particularmente representativa del modo de mirar de los grupos dirigentes chilenos de la década de 1930, puesto que se se narran los avatares de la joven Teresa Iturrigorriaga, una joven de clase alta, por mantenerse en el ámbito social de la elite, para lo cual debe guardar las apariencias y esconder su situación económica pauperizada. La protagonista lucha para no ser excluída de su círculo social más cercano, transformándose en una suerte de Madame Bovary que no se somete a dejar de ser parte de la elite. Todo esto, durante la década de 1930, en medio de una situación política inestable debido a las consecuencias dejadas por la crisis de 1929. En ese momento, Chile está en poder de ese grupo social privilegiado, primero latifundista, luego industrial y hoy mercantil, manipulador de la especulación y, en muchos casos, de las colusiones.

Los grupos económicos se reproducen en muchas ocasiones a la más antigua usanza feudal ello como dato estructural funcional y no como opinión respecto del asunto, como diría Claude Levi Strauss por medio de la Circulación de mujeres (1995), son los matrimonios y los parentescos, el

\footnotetext{
«La burguesía no puede existir si no es revolucionando incesantemente los instrumentos de la producción, que tanto vale decir el sistema todo de la producción, y con él todo el régimen social. Lo contrario de cuantas clases sociales la precedieron, que tenían todas por condición primaria de vida la intangibilidad del régimen de producción vigente. La época de la burguesía se caracteriza y distingue de todas las demás por el constante y agitado desplazamiento de la producción, por la conmoción ininterrumpida de todas las relaciones sociales, por una inquietud y una dinámica incesantes» (Marx y Engels 18).
} 
dispositivo por el cual las clases siguen imbricadas simbólica, económica y políticamente como siempre, aspecto que fundamenta la renovación funcionalmente eficiente.

Desde una lectura situada en una teoría crítica de la sociedad y la cultura, tanto desde la teología y filosofía de la liberación como del enfoque descolonizador, podemos hoy hacer uso de los instrumentos analíticos de las ciencias sociales para interpretar desde una filología transdiciplinaria. El libro La Chica del Crillón ostenta la desmesura y la crueldad de su particular lucidez, sagacidad de una lectura del mundo del autor empírico que hace al personaje dar voz a un autor textual, por cierto, capturado abiertamente en las distinciones que las clases sociales adquirieron. Pero el autor retrata en su libro a un grupo social que, paradójicamente, al mismo tiempo es defendido.

Hoy, contamos con categorías como las de «capital social» creada por Pierre Bourdieu (1992), que nos dicen que esos capitales no se logran con la educación, el mérito, el trabajo el estudio o el esfuerzo, sino que son capitales pertenecientes a compartimientos estanco, una suerte de dulce condena para la «elección de los elegidos». En el de Chile, hoy como en el de la primera mitad del siglo $\mathrm{XX}$, segmentos de los grupos dominantes van y vienen, el poder económico pasa de mano en mano junto al poder político, pero la casta no se desdibuja ni se anula, un individuo puede vivir en la pobreza, como la heroína del texto que analizamos, pero rápidamente puede recuperarse, casi como una predestinación, el final feliz de este libro.

Y comenzamos así, por el final de este relato, por la restitución del poder económico como destino ineludible de la señorita que en la miseria jamás se alejó de su clase en sus formas rituales y simbólicas. La chica del Crillón pudo ser humillada, pero jamás fue del todo expulsada y nunca abandonó su casta. Ni la educación o el trabajo habrían hecho que otra mujer adquiriera ese estatus. Es por esto que ella lo recupera casi como una restitución simétrica para que el orden de la vida siga su curso normal. El disciplinamiento en la normalización es un destino que resulta una constante en el Estado nación chileno y este libro no hace más que retratarlo, con lucidez y crueldad, porque Chile es Chile, y es 
un integrante de la familia Edwards ${ }^{5}$ quien lo escribe, comenzando así la novela:

Hace poco llegó a La Nación una dama joven, de tez trigueña, boca bien dibujada y ojos de indefinible hermosura oriental; en toda ella había algo de palmera y de turpial; sin embargo, era chilenísima, y lo exótico de su aspecto venía a ser una de esas rarezas comunes en la naturaleza chilena, donde al pie de Los Andes se dan paisajes sevillanos.

Después, leí el diario y quedé sinceramente estupefacto. Si la novela está ligada a la ciencia y a la sociología, ésta contiene un valor inapreciable. Se trata de nuestra época, vista en su entraña, aparte de la aridez de la estadística, del grisáceo abanderamiento de la política y de la confusión de pretensiones literarias. Tengo el deber de publicarlo, y lo hago sin reservas, desde el momento que la autora disfrazó su nombre y el de las personas que intervinieron directamente en su vida. De otra manera, el caso sería motivo de escándalo. (7)

\section{La soledad que se sobrelleva}

La ilusión de la «democracia de los consensos» se ha visto repetidas veces contradicha y traicionada en la historia de Chile, desde el concepto de democracia parlamentaria, hasta el modelo de democracia comunicativa de la Concertación de Partidos por la Democracia. Chile fue recientemente pensado en centros académicos como FLACSO $^{6}$ y $\mathrm{CLACSO}^{7}$ para la redemocratización, ya que desde la crisis del salitre y el modelo de sustitución de importaciones luego del gobierno de Carlos Ibáñez del Campo, y los decenios radicales por medio del ensayismo histórico y literario. El consenso comunicativo habermaseano (Alvarado

Familia Edwards, dueños de El Mercurio, el diario más antiguo de habla castellana. Plutócratas en Chile desde el siglo XIX, han sido un bastión en la dominación oligárquica, tanto por su diario, y la cadena de periódicos de los que son propietarios, como también por sus inversiones en diversos ámbitos. Su trayectoria familiar incluye desde el desprecio y abandono al poeta Rubén Darío en el siglo XIX hasta su oposición anticonstitucional al gobierno de Salvador Allende. La familia fue uno de los soportes de la dictadura pinochetista y de sus violaciones a los derechos humanos. Ello, por su acción en pro de la dictadura y sus omisiones. Hoy siguen siendo un bastión de la derecha económica y por lo tanto, desde su capital social y económico, un clan sostenedor de las desigualdades en Chile del siglo XXI.

6 Facultad Latinoamericana de Ciencias Sociales.

Consejo Latinoamericano de Ciencias Sociales. 
y Santander, 2003) parece una reedición del modelo de Estado nación democrático eurocentrado que enarboló la elite. Así, en nuestra opinión, termina primando la apelación angustiosa al orden, ello por sobre la voluntad de participar y de acoger a otros y otras en la participación.

En el modelo de una filología crítica desde el análisis retórico (como en el caso del aporte de Paul de Man, 1990), podemos decir que la novela La Chica del Crillón da cuenta de algo que fue actual para 1934 y es actual para 2016, esto es que la elite político económica tiene poder sobre la base de la reproducción de castas, reproducción que se realiza en dinámicas autónomas, pero que no involucran ni la meritocracia ni el ascenso social abierto a las mayorías, pues solo unos pocos pueden alcanzar el éxito económico y social, vale decir, aquellos que son parte de castas que por apellidos, herencias y capitales sociales, se reproducen en la política, la economía y en alguna medida en la cultura. El análisis de esta obra de Joaquín Edwards Bello al ser realizado desde una dialéctica entre texto y contexto da cuenta del mismo tipo de articulación de conciencia de la periodista Catalina Edwards, al opinar del sistema previsional chileno que citamos en el epígrafe de este artículo. No hay maldad, sino una mirada que más que ideología de clase es una cosmovisión impermeable, que ha sido eficiente en nuestro sistema de mantención de castas. $\mathrm{La}$ Chica del Crillón tiene razón, ella vuelve a su origen, y el destino la hace regresar casi por un designio divino o por la necesidad generalizada y transclasista de certidumbre, tan perenne y tan propia de un sentido común articulado desde los órdenes discursivos predominantes y poco dados a mutar, sólo se trata de un orden social que da giros pendulares sobre sí mismo.

El análisis de la novela puede dar lugar a numerosas lecturas. Sin duda, es un hito desde el punto de vista meramente estético en la historia de la novela realista chilena; también es un texto que, por su estilo, ha merecido elogios, particularmente, por ser una voz masculina heterosexual que toma la voz femenina de la primera mitad del siglo $X X$, específicamente la voz de una mujer representante de la oligarquía en decadencia y en proceso de empobrecimiento. Es sorprendente ver en este texto cómo un autor es capaz de asumir lo que hoy podríamos identificar como «perspectiva de género». Antes de los estudios culturales, y de la aparición del segundo sexo de Simone de Beauvoir (1949), Joaquín Edwards Bello fue capaz de situarse en la voz del segundo 
sexo, en un segmento de clase específico, propio a él como autor empírico perteneciente a la oligarquía nacional; por lo mismo, intentó ser una voz polifónicamente armada en su retórica como sistema de valores expuesto en su metalengua, por lo que su escritura fue capaz de dar cuenta de las diversas contradicciones del género femenino y de su clase.

Esta novela nos hace recordar el uso del alter-ego usado por Fernando Pessoa, aunque se trate de géneros literarios distintos. No se trata solo de tomar la voz de la mujer, o de cualquier otro tipo social, sino de posesionarse de sus contradicciones, sin evitarlas, o, en el mejor de los sentidos, explotándolas; ningún relato, ni periodístico ni etnográfico, ni literario, puede aspirar a asumir la totalidad de la identidad del otro narrado, justamente porque, como dijera Rimbaud y reafirmara Lacan, «yo es siempre otro...».

Dejando un rollo de manuscritos sobre la mesa, dijo: -Me han ocurrido cosas extraordinarias, las que confieso en este diario. No soy poetisa. Creo que mis confesiones constituyen una novela más interesante que aquellas que las niñas del Crillón leen en la cama, comiendo chocolates. Estúdiela, y si la cree buena, publíquela.

Iba a decir algo, cuando la bella desapareció. No la vi jamás, ni la he vuelto a ver. Es verdad que no frecuento los sitios donde va el gran mundo... (Edwards Bello 7)

En la historia de la literatura, esta obra tiene su antecedente más digno en Gustave Flaubert, y específicamente en Madame Bovary (1856). Preguntarse por el personaje en el que se inspiró Edwards Bello es tan absurdo como la pregunta que se le hizo en un juicio al escritor de la novela francesa: ¿Quién es Madame Bovary? Es por eso que, en un sentido analítico, Madame Bovary es Flaubert, y la personaje principal de Joaquín Edwards Bello, en la obra analizada, es el propio Joaquín Edwards Bello, no porque se comparta el mismo género, sino porque Edwards Bello realiza una auténtica etnografía de la condición de género femenino, de su clase, y por tanto, los ojos, los oídos, de toda una vida de experiencia, de un «Edwards» y de un «Bello», convirtieron a los sentidos de nuestro autor en el instrumento privilegiado de un «estar-allí», a la manera de la etnografía realizada por la antropología de esa misma época, aunque probablemente, nuestro autor ni siquiera lo sospechaba. 
Joaquín Edwards Bello es la chica del Crillón, porque explora en las más profundas sinuosidades de una condición de género desmedrada, pero del mismo modo, posesionada en su rol. Como dijo Vargas Llosa (2008) de Madame Bovary: ella es una heroína, no porque sus acciones sean todas moralmente legítimas, sino porque se hace cargo de sí misma y su destino, y echa manos de todos los recursos socio-culturales que posee.

\section{El delgado hilo del capital social}

Como ya afirmamos, decir que Chile es una sociedad de castas es dar cuenta de algo absolutamente evidente: lo fue en la primera mitad del siglo XX, y lo sigue siendo hoy, aún más, en la primera mitad del siglo XXI. $\mathrm{Al}$ respecto, la misma protagonista señala lo fácil que es «caerse» de una clase, salir de ella en caída libre. La chica del Crillón es una descendiente de castellano-vascos que pertenece a la más conspicua oligarquía chilena, no obstante, su padre, debido a malos negocios y a su ineficiencia para sobrevivir dentro de su estrato socio-económico, se empobrece:

[...] Para el caso diré que me llamo Teresa Iturrigorriaga, y será la única mentira de mi narración. Uso un apellido vinoso y sin vino, es decir: soy aristócrata y sin plata. Vivo con mi padre enfermo y una vieja cocinera, a quienes mantengo.

Antes éramos ricos y habitábamos un palacete de la calle Dieciocho, en cuyo jardín cantaban los pájaros; ahora vivimos en el extremo de la calle Romero, y los arpegios aéreos han sido reemplazados por las actividades de los ratones en el entretecho. Nos rodean los cités y conventillos; las casas de adobes tienen parches, grietas, y se apoyan unas en otras como heridos después de la batalla. [...] Yo no puedo decir a mis amigas dónde vivo y me veo impulsada a ocultar este domicilio. Se vive de apariencias, y la pobreza va estrechamente unida al prestigio [...]. (9)

Aquí se encuentra el punto esencial de la novela, empobrecerse es perder el capital económico, pero no significa necesariamente perder el capital social. Joaquín Edwards Bello da cuenta de una paradoja sociológica, que aún tiene validez para nuestro país: el dinero se puede obtener o perder, pero el estatus social es algo que, una vez obtenido, 
puede mantenerse, no obstante, es muy difícil de alcanzar, pues ni siquiera el enriquecimiento logra por sí mismo la posesión del capital social de la oligarquía chilena. Esto lo ha vivido, de manera ostensible, la actual plutocracia comercial chilena, que en cierto sentido, es despreciada por la oligarquía de sangre.

\section{De la trama}

Si intentamos resumir esta novela, se trata de la historia de vida que, supuestamente, entrega a un periodista una muchacha con un nombre castellano-vasco conspicuo, pero que se encuentra en la más absoluta pobreza. Ella escribe por placer, y explícitamente no tiene ambiciones literarias, pero narra su historia con una nitidez que llega a ser desgarradora.

La protagonista acude constantemente al salón del hotel Crillón porque es lo que la mantiene «dentro», y lo que no solo le permite mantener vínculos afectivos, sino que también aquello que le permite sobrevivir por medio de pequeños negocios que caen incluso en el nivel del fraude, como es el caso de la venta de obras de arte adulteradas. Hay un momento particularmente importante en el nudo argumental, en el cual sus contertulios oligarcas le hacen una broma de mal gusto, diciéndole que ella tiene mal olor. Pero lo que los bromistas no podían saber, es que ella habitaba una vivienda donde no contaba con las condiciones higiénicas mínimas. Lo relevante del relato de Edwards Bello es que, si bien, es su clase quien la maltrata, también es su propia clase la que la salva a través de una buena señora de la alta burguesía, la señora Rubilar, que la reconforta y que tiene curiosamente como misión vital ayudar a bien casar a muchachas de baja clase media.

La historia prosigue como una suerte de venganza del autor respecto de su propia clase, pues uno de los personajes, Doña Ismenia o «La pecho de mármol» (nombre con que se la conoce en el ambiente prostibular), enamorada del padre de la heroína y dueña de un prostíbulo exitoso, le entrega a la muchacha todos los bienes que ha ganado en su vida, incluyendo, entre ellos, un fundo en el sur de Chile. La historia concluye con el viaje de la señorita Iturrigorriaga a dicho fundo, contexto en el cual se encuentra con una revuelta de campesinos e indígenas, que por lo que anota el narrador, y por la época, no es difícil identificar con el 
levantamiento de Ranquil ${ }^{8}$. Pero no hay ninguna solidaridad, ni empatía ni compasión en el personaje de Iturrigorriaga; y por ello tampoco la hay en Edwards Bello autor, pues el narrador, a través de sus ojos, ve en los revoltosos a una chusma anárquica y criminal. Poco le importan a nuestra dama los asesinatos de los rebeldes, ya que, para ella, la puesta en orden a sangre y fuego es una restauración necesaria. La novela concluye como un cuento de hadas: la chica del Crillón se casa con un latifundista, hombre que la defiende en esos difíciles momentos. De este modo, ella recupera su estatus económico, sin perder nunca su capital social, vale decir, no es su nivel educacional, sino básicamente, su genealogía, lo que la hace digna de un buen casamiento y de una buena vida futura. No hay en Joaquín Edwards Bello una expresión de sensibilidad frente a las demandas campesinas o indígenas, y parece en esta novela, reiterar lo que ya planteaba en su novela El Roto (1920), que lo único interesante que ha producido el mundo popular son los prostíbulos, como si la noción de sacrificio como cosmovisión (Bataille, 1996), como dolor y muerte necesarios para la mantención de los ciclos fuera para él un mecanismo naturalizado.

\section{Del arte de la novela}

Quizás uno de los momentos más altos de la novelística contemporánea fue el que logró Milan Kundera en su obra maestra Lainsoportable levedad del ser (1984). Kundera llega a un clímax narrativo cuando, a la vez que se produce una ruptura amorosa en la pareja asociada a las infidelidades del marido, irrumpe un temblor físico provocado por los tanques rusos que ponen fin con ello a la primavera de Praga. El movimiento telúrico va a la par del terremoto emocional de la crisis de la pareja, donde la

\footnotetext{
La Masacre o Levantamento de Ranquil se produjo en junio y julio de 1934, cuando grupos de campesinos e indígenas mapuches de la Provincia de Malleco, Chile, se sublevaron en contra de los abusos de los patrones, provocando una revuelta de proporciones insospechadas. Los orígenes de la rebelión son múltiples, por una parte, el masivo plan de colonización impulsado por el Gobierno de Chile entre 1881-1914 que tenía como objetivo la instalación de quince mil colonos extranjeros (alemanes, franceses, suizos, bohemios, etc.), lo que tuvo como consecuencia la disminución del patrimonio de los pueblos mapuche, pehuenche, huilliche y lafkenche, quienes presionados por la continua enajenación de tierras por parte del Estado de Chile se convirtieron en empobrecidos agricultores del sector de Lonquimay. Otro de los argumentos, se encuentra en las condiciones de semi-esclavitud que llevaban los campesinos y los obreros del sector de Lonquimay. Estas condiciones eran en ciertos sentidos similares a las que se llevaban en las plantas salitreras del norte de Chile, donde los trabajadores se encontraban sujetos a la total autoridad de su empleador. Pese a que se realizaron conversaciones entre las partes, fuerzas de Carabineros de Chile empezaron a hostigar a los ocupantes (Radio Viaducto párr. 1-7).
} 
pregunta implícita es: ¿qué es más importante, una ruptura amorosa o una invasión militar? En la metalengua de Kundera, ambos asuntos poseen igual relevancia, aunque no hay que confundirse: no mantienen una relación homológica, ni la crisis matrimonial es producto de la crisis política, ni viceversa, pero ambas situaciones poseen en el contexto de una gran novela, una importancia fundamental, y los hilos que las unen son los propios de la visión multivariable, propia de las ciencias humanas, que entienden que el reconocimiento de relaciones causa-efecto es solo un modo de interpretar muy logocéntrico, porque para cada fenómeno, sea social o íntimo, existen muchas causas y muchos efectos distintos. Asociado a lo anterior, la originalidad de Joaquín Edwards Bello en esta novela, no consiste en entregarnos una caracterización sociológica que tienda a ser políticamente correcta, a lo menos a los ojos de un lector del siglo XXI; el autor nos presenta a una clase social en decadencia y en proceso de adaptación, pero haciendo explícitamente una opción de clase, que sin duda no es la de la clase media, ni la de los sectores populares.

Observada con un telescopio, la trama de esta novela nos presenta la decadencia de la oligarquía minera y latifundista, básicamente, debido a la crisis, una «crisis de la polis oligárquica» (Morandé, 1984), ya que se trata de la experiencia de un padre que es incapaz de mantener la fortuna familiar. Sin embargo, representa también la decadencia de toda una clase que pierde sus privilegios, o al menos algunos de ellos, a manos de las emergentes burguesías comerciales e industriales.

La explicación socio-estructural nos permite entender en profundidad la novela, puesto que el personaje principal, aunque vive esta decadencia, es tremendamente proactivo respecto de ella. Lejos de deprimirse, incluso por la experiencia misma del hambre, la señorita Iturrigorriaga cuida su vestimenta a la hora de presentarse en público, y el Hotel Crillón es el escenario donde ella, noche a noche, permite que su habitus de clase (Bourdieu, 2002) se mantenga: el autor ejemplifica esta situación narrando como se encuentra en la pobreza con su padre enfermo y trabajando como sirvienta sin prácticamente ninguna remuneración por ser parte de la familia para la que trabaja. No obstante, el personaje no sucumbe a la desesperación, como tampoco pierde lo que ella entiende por dignidad, ya que sabe conversar, hablar, vestirse, callar, opinar y embaucar, artilugios que utilizará en pos de un fin superior: sobrevivir. 
Resulta, particularmente interesante, cuando la chica del Crillón nos dice que a las mujeres de su clase «nadie les da trabajo», y que sería más fácil ser representante de la clase media, que vivir esta situación de simulacro que, sin embargo, es simulacro respecto del ocultamiento de la pobreza, pero no una simulación de un habitus de clase que se sostiene desde un capital social que pende de un hilo. Hay algo de resentimiento social, invertido en la conciencia de sí al no tener los medios para ubicarse en su extracto de clase, un resentimiento ferviente ante lo moderno y el cambio, aspecto que Edwards ilustra así: «Mi apellido es demasiado aristócrata para que me den trabajo en estos tiempos; las revoluciones ideológicas han desacreditado a la clase alta, quitándole medios para demostrar que todavía sirve para algo» (4).

Se supone que ella está enamorada de un diplomático español, a quien los avatares del destino le harán salvarlo, para luego alejarse definitivamente de él, pero este diplomático representa, justamente, a la oligarquía ociosa, que tampoco es la clase a la cual representa y defiende el autor; su personaje es una heroína, porque es capaz de sobreponerse a las circunstancias y vivir situaciones de una contradicción extrema, como por ejemplo, pedir ayuda para los pobres, como buena dama de sociedad, aunque en lo fundamental, la señorita Iturrigorriaga es tan pobre como los que intenta ayudar, pero la caridad que ella practica no es solidaridad de clase, sino por el contrario, una práctica piadosa que se emparenta con lo religioso, y que es otra práctica más, propia de su habitus de clase.

\section{La sorpresa del eterno retorno}

Esmuy interesante pensarque, mucho deloque relata Joaquín Edwards Bello, es propio de la sociedad chilena actual, ya que, si la oligarquía terrateniente de finales del siglo XIX la componían aproximadamente cincuenta familias, las cuales rotaban en los más altos cargos públicos y eran las propietarias del poder económico, podemos ser irónicos y decir que en Chile se ha producido un vertiginoso proceso de reducción de la complejidad, y hoy en día, son solo diez las familias más acaudaladas. Para ellos, los grupos dominantes de hace casi un siglo, Chile es un país aburrido, justamente por la estabilidad de su papel y riqueza, que no veían amenazada, ni siquiera por los movimientos sociales de la década del treinta del pasado siglo: «Asegurar que Chile es un país aburrido 
se ha hecho un deber entre la gente cursi; por eso agradezco cuando la señora Rubilar alaba nuestras fiestas y costumbres» (Edwards Bello 16).

Lo preocupante es que el contexto de la novela es el del ascenso de la clase media, pero hoy, esa clase media es demográficamente más importante, pero políticamente menos poderosa; cabe preguntarse ¿Podría hoy, una muchacha empobrecida, que pertenece a las familias de la alta burguesía comercial, mantenerse en su clase, a pesar del empobrecimiento? Lo más probable es que no, porque hoy tienen menos importancia las formas más íntimas del hablar, del vestir y del callar, y si la ostentación es el baluarte de la respetabilidad para los grupos dominantes, entonces, la pérdida del capital económico es hoy una caída absoluta. Quizás, las nociones de elegancia, estilo, modales, sean algo que ya los grupos dominantes chilenos perdieron. En la novela de Edwards Bello, un detalle en la conducta, un olor, un modal, una prenda de ropa, cualquier tropiezo menor significa la caída:

Me invitó a quitarme el vestido y hacer lo mismo, diciéndome que era el último invento de tocador, para evitar la transpiración de las axilas. Este refinamiento era totalmente nuevo para mí, y me intimidó. Ella misma se ofreció para desvestirme, pero a mí me dio una gran vergüenza la idea de que viera mi pobre ropa interior y mi vestido gastado bajo las mangas. (19)

Las nuevas chicas del Crillón, probablemente sean hoy mujeres que aparentan tener riqueza, para lograr un buen casamiento, porque al parecer, la circulación de mujeres por medio de las estructuras de parentesco sea lo principal que queda de la polis oligárquica chilena, y que resulta algo más próximo a las estructuras de parentesco, que las formas de pluriclasismo de una sociedad moderna como las entendía Claude Levi-Strauss (1995). La sociedad chilena no es moderna, porque los capitales sociales se encuentran esclerotizados, y la riqueza es la única circunstancia que da prestigio, aunque no deja de ser por eso, una circunstancia. La clase media sigue siendo un mal necesario o inevitable para la oligarquía, pero esa clase media en la época donde la novela se desarrolla siempre rescata blasones ilusorios de hidalguía, rememorando algún conspicuo antepasado, generalmente ficticio y muy remoto:

-Nuestro apellido -dijo, como si eso la preocupara hasta hacerle daño- debiera escribirse Sánchez de Cepeda y 
Ahumada, como que es el mismo de Santa Teresa de Ávila, cuyos hermanos, es muy sabido, se radicaron en Chile. Ya ve: yo soy Cepeda también por el lado materno... y ahí está la santa. Dicen que se me parece.

-Es verdad -asentí, mirando el cuadro de la santa, que su larga mano me señaló. (Tenía su mismo óvalo de huevo duro).

Cada vez denotaba su extrema sensibilidad respecto a linaje y su dolor de no llevar apellido vinoso. Pocas veces he tenido la sensación de mi valor de ser Iturrigorriaga. (33)

Probablemente el Chile de Joaquín Edwards Bello tendía más hacia una democracia moderna, al menos como utopía para soñar la ciudad futura. Sin embargo, hoy podemos ver una extrema segmentación social y económica de la sociedad chilena, fundamentalmente por la autocracia que iban adquiriendo en aquel tiempo los sectores populares. Por tanto, en nuestra lectura de La Chica del Crillón, más que encontrarnos con un espejo, nos encontramos con un retrato en sepia que, curiosamente, tiene contornos mejor delineados que los del espejo borroso de la sociedad chilena actual.

\section{El padre como deserción y fuente de angustia}

La figura del padre en esta novela es, principalmente, una añoranza, y no nos referimos solo a la muerte del padre físico, sino a la debilidad del orden social falocéntrico, que hubiese conferido estabilidad social y emocional a la señorita Iturrigorriaga, sino también a la figura de la familia falocentrada. Los referentes familiares del personaje principal son siempre mujeres que pertenecen a la oligarquía, y que la apoyan, como es el caso de la señora Rubilar, o el de las matronas del clan familiar que la han despreciado, y que luego la aceptan solamente porque ha recuperado la riqueza; el personaje del diplomático español es un ser débil e inseguro, casi en homología a la figura del padre de la señorita Iturrigorriaga. El hombre es débil, tanto en el contexto parental como en el amoroso, lo que a la luz de nuestra lectura implica que esta novela escenifica la debilidad de un orden social que entregaba certidumbre. Solamente la aparición del latifundista, quien parece provenir del mundo de lo natural, del campo, y que está remotamente emparentado con ella, 
según discurre la madre de este hacendado, parecen ser una recuperación de la figura del padre como restablecimiento de la estabilidad del orden emocional y social, pero desde la apelación a un orden latifundista ya en decadencia hacia el año 1935. Este aspecto no es de menor importancia; en la hipótesis psicoanalítica tradicional (Lacan, 2006) que sostiene que el padre es el sostén simbólico y la figura de la ley, vemos a nuestra personaje siempre frágil frente a las circunstancias, hasta el momento en que cabalga abrazada al hacendado que la protege, figura literaria bastante prosaica, si consideramos la fineza narrativa de Edwards Bello; el resto es siempre de una estabilidad precaria, en tanto ninguna mujer parece darle el orden y la estabilidad necesarias, y son, en contadas ocasiones, las que resultan en un remanso en el mar de una tremenda angustia existencial. Solo el hombre proporciona certidumbre absoluta, aunque es una ausencia, pues incluso en la novela, en el encuentro con quien será su marido podemos ver esta función:

-Aquí, todo lo que la vista abarca, hasta el pie de la cordillera, es mío -dijo don Ramón. -¿Qué hora será? Puso la mano contra el sol, levantó el dedo del corazón, y juzgando por la sombra que proyectaba en la palma, dedujo: -Las diez y media. Hemos corrido desde las cinco. ¿Está cansada? -Sigamos. (9)

Resulta interesante resaltar la figura de la amante del padre, Doña Ismenia, motivo de vergüenza para éste, pero quien, no obstante, es la que le restituye a la protagonista la riqueza que el propio padre no fue capaz de proveerle. Se trata de una mujer rica, pero también pecadora, que redime sus culpas de dos formas: entregando toda su fortuna a la señorita Iturrigorriaga, y retirándose a un convento en una suerte de «proceso idolátrico» de la memoria del padre. Cabe entonces preguntarse ¿está pagando sus culpas por haberse enriquecido en la prostitución, y por la prostitución misma, o por haber hecho lo que el padre-hombre no pudo hacer por nuestra personaje?

No creemos que la biografía del autor de una obra explique cómo ésta estructurará una retórica y por tanto, en términos Paul de Man, a un sistema axiológico, pero el origen aristocrático de Joaquín Edwards Bello le impidió quizás entender que, en el contexto de la cultura popular, se puede vivir sin padre. Desde los argumentos de Sonia Montecino, hasta los trabajos de Gabriel Salazar, queda demostrado que, simbólica 
y económicamente, «el huacherío» (Alvarado Borgoño, 2016) no es la excepción sino la regla en el estilo de vida de la cultura popular, y más aún, históricamente, desde la conquista de América y Chile, el padre es para las grandes mayorías, quien fecunda y luego abandona. Por lo tanto, el falo totémico es más bien la figura de la madre sola, que no vive necesariamente en la angustia existencial por la carencia del padre físico. Pero Joaquín Edwards Bello escribe desde los códigos de su clase social de origen, en los cuales la ausencia del padre es motivo de escándalo y minusvalía: «En el centro vuelvo a ser la Teresa Iturrigorriaga, parienta de políticos, de cosecheros, de abogados. Mis padres, mis abuelos, mis tatarabuelos fueron ricos, por eso sé hacerme la oligarca, aunque vivo al día, con todos los inconvenientes y ninguna de las ventajas de las ricas» (4).

La ausencia del padre, en tanto proveedor e imagen dominante, es siempre en esta novela causa de angustia. La señorita Iturrigorriaga sobrevive al padre débil, en términos de que es capaz de asumir su debilidad, pero esto implica un inmenso costo emocional para ella: pareciera ser que la llegada de la riqueza fuera la resurrección del padre biológico, bajo la forma del dinero entregado por la amante pecadora, mujer que se retira a la oración y a la soledad. Si habláramos de la cultura popular, veríamos que la ausencia del padre es más bien una constante, y que una mujer sin padre no es una mujer angustiada necesariamente por ello, pero en este caso, el orden latifundista es un orden falo centrado, en el cual la ausencia de la madre de nuestra protagonista, no es la causa de la angustia existencial. Pero nuestra personaje no es portadora de la cultura popular, no hay en ella una imagen materna, pero sí una profunda femineidad, más bien construida sobre la audacia para proteger al padre; al parecer la riqueza y el marido son, para Joaquín Edwards Bello, el modo en que la protagonista puede recuperar la estabilidad emocional y el prestigio social. En el mundo popular, ninguna de las dos cosas, riqueza o marido, son indispensables.

Deseamos destacar la relación que se establece entre angustia existencial y paternidad: el padre es débil y pobre, por lo tanto ella es una mujer que, no siendo débil, es un ser angustiado; pero como se ha dicho, ello se corresponde con las formas de estructuración psíquica de las mujeres de la oligarquía de su época. Es indudable que si no hay una madre protectora que ocupe ese espacio para la generación 
de certidumbre, se genera una personalidad femenina no débil, pero si angustiada por la carencia. Si intentamos proyectar esto a un nivel transclasista, podríamos decir que cualquier mujer podría ser tan heroica como la señorita Iturrigorriaga, pero en toda mujer que vive esa situación está rondando el síntoma de la ansiedad mórbida. Psicoanalíticamente la angustia se corresponde con los temores esenciales a la muerte, al ridículo y a la locura; en la narración que estamos analizando, el temor al ridículo supera a los otros dos, pero domina la personalidad de la personaje; ella actúa en torno al aparentar, y vive su vida en la defensa del capital simbólico constituido desde la pura apariencia que le provee el capital social. Hay algo muy propio de lo femenino que trasciende los años. Si en esta novela la mujer existe en tanto presencia o ausencia del padre, ella puede ser valiente y superar la carencia, pero la angustia le pisa los talones, y el dinero es fuente de certidumbre, seguridad, restitución del lugar perdido, no importa cuál sea su origen, aspecto que Edwards describe así:

La señora Ismenia tuvo pensión de artistas, y este negocio me parece tan lícito como la compraventa, los remates o los cambios de gobierno. Además: no comprendo que el haber yo recibido una fortuna haga sufrir al decoro de la familia; según ustedes, nuestro estado honorable y decoroso es el de ser pobres como ratas. [...]. -Ya sabes que a ella la llamaban la Pecho de Mármol... (103)

\section{No podía escribir otro final}

El final de esta novela es su principio, la admiración no disimulada ante la dignidad mayestática de la aristócrata descendiente de vascos venida a menos. Esta heroína es heroica y al parecer no cae en contradicciones a los ojos del autor empírico, pues su final es su principio, su valentía y su orgullo, que nunca es desmesurado pero si abundante, es la señal inequívoca de la restitución de la posición de clase ineludible. Pareciera predecir desde el principio que, por un acto de magia, como en un cuento de hadas o en una telenovela moderna, todo volverá no a su sitio, sino al sitio donde debiera haber estado. Hay un orden ideal subyacente, donde la estamentalización es la ley implícita e inconsciente, donde quien tiene el poder y los privilegios los mantendrá, y la restitución final del dinero 
y del abolengo por la mantención del linaje y por casamiento con un hacendado -remoto pariente suyo-, hacen de la heroína un sujeto de continuidad: el mundo vuelve a reconstituirse, a girar sobre su propio eje como es debido.

Joaquín Edwards Bello nos muestra un mundo donde las clases y sus segmentos tienden a ubicarse y reubicarse en la lógica de una racionalidad latifundista y patriarcal, aunque sea una mujer el epicentro del relato. La dignidad no es restituida por el dinero aportado por su madre adoptiva, dueña al fin de cuentas de un prostíbulo, sino por el matrimonio para seguir con el orden de su casta. Es la oligarquía que gira sobre su propio eje, y en los avatares de los cambios sociales y de los procesos de modernización hay una fisura que hace que ese eje tienda, en la metalengua de esta novela, no a la recuperación de un pasado ideal, sino más bien al reordenamiento de una racionalidad transhistórica que devuelve a su lugar las posiciones de clase. Se trata de una metafísica implícita en la metalengua: los campesinos demandantes son lumpen alzado y delictual, instigado por extraños; no hay legitimidad en la demanda social $y$, a pesar de que el autor se burla de su oligarquía alienada y hueca, hay un orden latifundista que debería ser restituido según la lógica de este relato; por último, en el plano de esta narrativa, hay valores que hacen que la miseria enfrentada con valor hagan a la heroína merecedora de la restitución de su sitial económico y social, que lejos está de generarle un sentimiento de empatía hacia los pobres:

-Señorita -me dijo-, la situación es muy mala. Tenemos huelga parcial en los ferrocarriles y levantamiento de colonos en toda la región. Desde que ocurrieron los sucesos de Lonquimay los campesinos andan sublevados.

Ya había notado que las caras de los hombres que ambulaban por la estación no eran nada tranquilizadoras. En el momento de conversar con el asustado jefe algunos borrachos se asomaron por la ventanilla, haciéndome morisquetas desvergonzadas. A eso me conducía un viaje largo y pesado. La muchedumbre en la estación comenzaba a rugir, recordándome las asonadas electorales. Algunas mujeres famélicas, desgreñadas, azuzaban a los hombres, hablando de reivindicaciones y de ultrajes. (122) 
Los privilegiados vuelven a ser privilegiados, porque en una ley implícita para el autor hay un eterno retorno. Todo cambia y todo continua, y la oligarquía chilena sigue siendo oligarca, ahora con dinero y prestigio, aditivos de un habitus de clase que tiene internalizado y que porta con valentía e insolencia. No hay ascenso social legítimo, no hay inmigrantes, clase media, comerciantes o pequeños empresarios, ya que son grupos que forman parte de un universo ajeno que no pertenece al edén al cual la heroína es restituida, casi por milagro y casi como si fuera un ley natural que define las relaciones sociales. «Los ricos también lloran», y los ricos que dejan de serlo lloran aún más. Pero para Joaquín Edwards Bello ese orden social oligarca se reconstituye para seguir con los ciclos de la naturaleza de lo social. en una suerte de antropología que entiende al mundo como siempre en transformación, pero en una lógica de continuidad que invariablemente será restituida. La demanda social es satanizada y se entrevé una oscura conspiración y no la expresión de una demanda legítima: «-¿Hay peligro todavía? -De día, más que de noche. Hay colonos sublevados. Gente mala y viciosa, que nos viene de afuera; ni uno solo es del Sur. Aquí, la gente es buena» (128).

\section{Conclusión}

Desde un punto de vista funcional en un análisis sociológico, la reconversión de una clase social es un fenómeno adaptativo y muchas veces eficiente. Más allá de la idea de progreso histórico, toda sociedad muta permanentemente y las clases que la componen cambian con ella, pues si así no lo hicieran no responderían a las necesidades históricas y contextuales. La Chica del Crillón no expresa un progreso histórico, sino que retrata el modo en que los grupos dominantes mutan sobre sí mismos, desplazamiento dinámico a lugares que les eran propios, ubicando otros nuevos y recuperando otros tantos.

La heroína de esta novela es un ejemplo casi idílico de una recuperación. En un final feliz nada importa el contexto histórico y sus injusticias, puesto que se hace justicia con la personaje principal y eso basta; la restitución es un giro de la oligarquía sobre sí misma, porque la señorita Teresa Iturrigorriaga no pierde su capital social y los derechos que el autor textual implícitamente le atribuye. Su resilencia y valor frente a la miseria y a los intentos de expulsión por parte de la 
elite económica, son el mérito que, en aquello que Vargas Llosa (2008) denominó como la «orgía perpetua», hacen de la especificidad de un personaje como tipo social, la merecedora -dentro de la racionalidad de los grupos dominantes de la época-, de la restitución del lugar que por su clase le corresponde. Según el crítico peruano, un novelista solo crea una historia a partir de su propia historia, resultando ésta del conjunto de experiencias secundarias de tiempos distintos unidos en la mente del autor. Según el principio flaubertiano, el punto de partida de la realidad ficticia es siempre la realidad real como la que vive el autor. En este sentido, el péndulo gira sobre su eje y, en el final de su novela, le toca su turno a esta suerte de cenicienta muy a la chilena.

Desde cada contexto es posible hacer una hermenéutica textual fusionando horizontes, fusión que va desde Joaquín Edwards Bello a nuestro presente. Ello nos genera una lectura en la cual vemos un texto que, como artefacto sociocultural, representa la alianza, no sin dificultades y mutuas descalificaciones, entre la oligarquía de la sangre y la tierra, versus la naciente pero pujante burguesía del comercio y la industria. Joaquín Edwards Bello no es neutral, por el contrario, asume una postura crítica que destaca la banalidad de ambas clases sociales, sus negociaciones, sus circulaciones de significados, de sentidos y de mujeres; pero no se cuestiona la injusticia estructural de su contexto, emanada del orden social latifundista, de los intentos de industrialización y de la crisis del salitre. El autor empírico naturaliza la pobreza citadina y ve como una expresión lumpenesca a los movimientos y revueltas sociales, siendo fiel a su clase, mientras que el autor textual narra desde la ironía y el descoyuntamiento, pero nunca desde el abandono de una visón clasista. Hay un momento en la vida de nuestra personaje, cuando se ve con dinero y descubre la banalidad del amado diplomático español, que es clave. Es el instante en que está más sola, pero también es el momento en que es más libre, ya que rehúsa el supuesto apoyo de la familia patriarcal y decide emprender un camino hacia el sur de Chile, en defensa de sus intereses económicos.

¿Podría nuestro personaje haber sobrevivido sin el apoyo de su futuro esposo latifundista? Desde una lógica contemporánea sí, ya que tenía dinero y una estructura de personalidad para usarlo en su bienestar. Pero Joaquín Edwards Bello no le podía proporcionar otro final a esta novela: una mujer sola y rica que no viviera en la angustia existencial, sería algo 
parecido a las chilenas populares dueñas de chingana, que durante el siglo XIX y la primera mitad del XX, desde la autonomía económica lograban la autonomía psicológica y la respetabilidad social, pero aquello solo le es permitido a los estratos populares y a la clase media. Para completar el círculo del falocentrismo se necesitaba un buen casamiento, es decir, la obtención definitiva de un padre protector: Joaquín Edwards Bello no podría haber imaginado otro final y ese es el epicentro de su retórica y por lo tanto de su metalengua. Su heroína, «primero muerta que sencilla».

\section{Referencias bibliográficas}

Alvarado Borgoño, Miguel. 2016. «La metafísica del huacho: Visita a la obra Madres y huachos. Alegoría del mestizaje chileno de Sonia Montecino». Literatura y Lingüística, no. 33, 2016, pp. 169-196.

Alvarado, Miguel y Pedro Santander. «'Matar al padre': Análisis discursivo de dos textos de la sociología chilena en período de dictadura». Literatura y Lingüística, no. 14 2003, pp. 135-157.

Bataille, Georges. Lo que entiendo por Soberanía. Barcelona, Paidós, 1996.

Bourdieu, Pierre. La distinción. Criterio y bases sociales del gusto. España, Gediza, 2002.

De Man, Paul. La resistencia a la teoría. Madrid, Editorial Visor, 1990.

Edwards Bello, Joaquín. La chica del Crillón. Santiago, Ercilla, 1935.

Kundera, Milan. La insoportable levedad del ser. Barcelona, RBA, 1993.

Lacan, Jacques. «Subversión del sujeto y dialéctica del deseo en el inconsciente freudiano». Escritos. J. Lacan. Obras escogidas I. Barcelona, RBA Coleccionables, S.A., 2006.

La mañana. «Catalina Edwards: funan a periodista de Mega por Twitter». Chilevisión.cl. 4 Agosto 2016, http: / / www.chilevision.cl/ matinal/ reportajes / catalina-edwards-funan-a-periodista-de-mega-portwitter/2016-08-04/115743.html.

Lévi-Strauss, Claude. «El análisis estructural en lingüística y en antropología». Antropología estructural. Barcelona, Paidós, 1995, pp. 75-95. 
. «La noción de estructura en etnología». Antropología estructural. Barcelona, Paidós, 1995, pp. 299-337.

Marx, Karl y Friedrich Engels. «Burgueses y proletarios». Manifiesto del Partido Comunista (1848). Digitalizado para el Marx-Engels Internet Archive por José F. Polanco en 1998. Retranscrito para el Marxists Internet Archive por Juan R. Fajardo en 1999, http: / / carpetashistoria.fahce.unlp.edu.ar / carpeta-1/ fuentes / la-belleepoque-y-el-capitalismo-global/fuente-1

Mignolo, Walter. Teoría del texto e interpretación de textos. México, Editorial Universidad Autónoma de México, 1986.

Morandé, Pedro. Cultura y modernización en América latina: ensayo sociológico sobre la crisis del desarrollismo y su superación. Madrid, Encuentro, 1984.

Radio Viaducto. «80 años de la Masacre al Levantamiento de Ránquil». Radio Viaducto FM 101.9, http: / / radioviaducto.cl/web/80-anosde-la-masacre-al-levantamiento-de-ranquil/.

Subercaseaux, Bernardo. «Prosopografía, Biografía Psicosocial e Historia Intelectual (A Propósito de J. V. Lastarria)». Universum, vol. 30, no. 2, 2015, pp. 251-262.

Vargas Llosa, Mario. La orgía perpetua. México, Editorial Alfaguara, 2008. 